\title{
European impasse over patients' rights directive may be at an end
}

Published at www.cmaj.ca on June 22

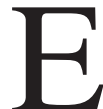
uropean patients are inching closer to having the right to receive health care in other European Union countries under a draft directive adopted by the health ministers of 27 member states.

But even if formally adopted this fall, the directive will not give patients carte blanche to receive treatment where they wish. Concerned about the impact on national health care budgets, the ministers insisted on including a proviso that will require patients to seek "prior authorization" from their national health care authorities if they are seeking treatment abroad that requires more than a one-night hospital stay, uses "highly specialized" medical equipment, or raises "safety or quality" concerns.

The draft directive also muddies the waters regarding the nation that is responsible for payment of health care costs associated with residents who are noncitizens. In such cases, it requires the patient's country of origin to foot the bill, even if he or she is now resident in the other nation. Essentially, countries will have to absorb the costs associated with providing health care to pensioners who have retired and reside in other countries with often warmer climates.

A previous 2008 attempt to develop a patients' rights directive ran aground when Spain balked at the notion of having to pay for costs associated with providing care to northern Europeans spending their golden years in villas along the Spanish coastline.

But the compromise provisos contained within the directive mitigated such concerns and Spain's Minister for Health and Social Policies now lauds the agreement.

The compromises, which were proposed by Spain, introduced improvements in key areas, claimed Trinidad Jiménez at a press conference follow-

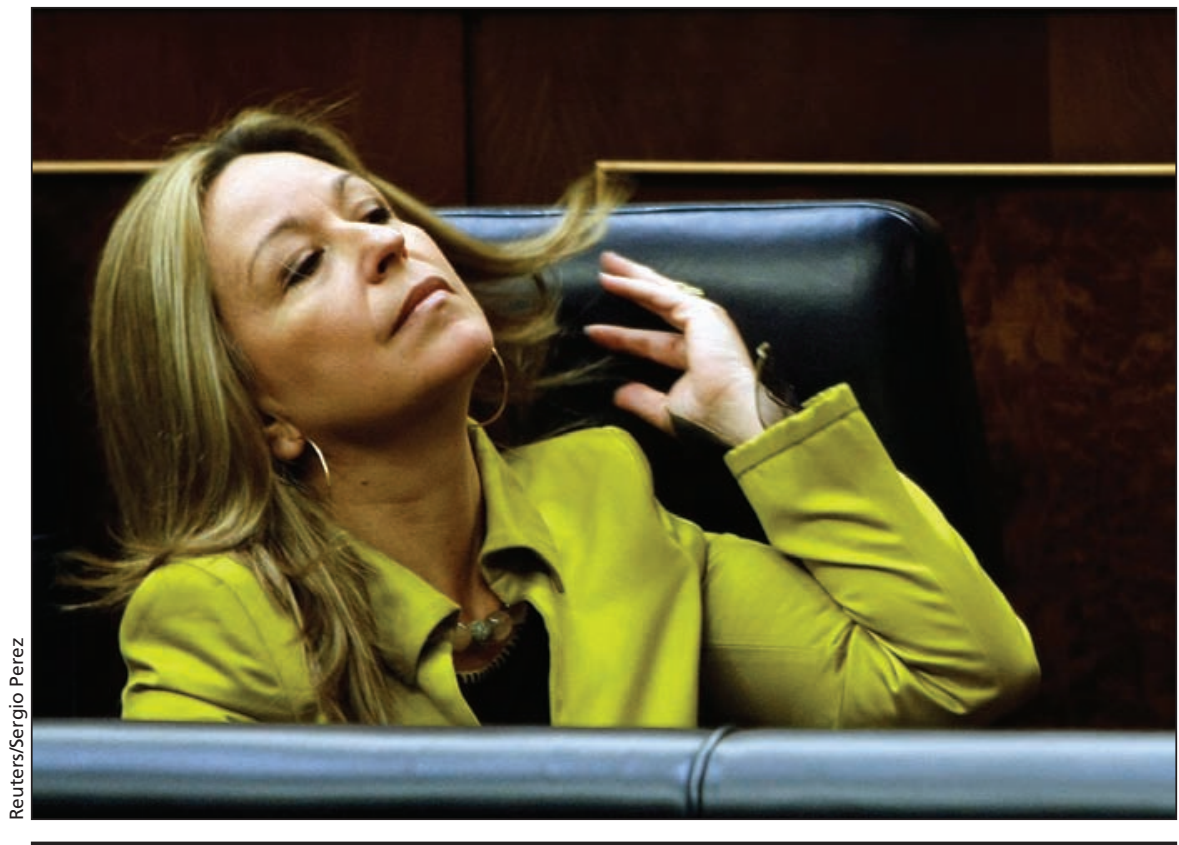

Trinidad Jiménez, Spain's minister for Health and Social Policies, brokered a compromise which broke an impasse over a proposed European patients' rights directive. Spain had balked at the notion of having to pay treatment costs for northern Europeans spending their golden years in villas along the Spanish coastline but under the compromise agreement, the patient's country of origin will foot the bill.

ing a meeting of the Employment, Social Policy, Health and Consumer Affairs Council. "It fine-tunes the general criteria for reimbursement and the prior authorization requirements to include quality criteria which are further steps towards providing patients with greater guarantees. The main progress in this area involves ensuring that public and private providers meet quality criteria defined by each member state, which will always ensure greater security for patients."

The European Union has been under pressure for more than a decade to develop a framework for patients' rights in the provision of cross-border health care as a result of a series of lawsuits brought before the European Court of Justice.

The court has repeatedly ruled since 1998 that patients have the right to be reimbursed for health care they receive in other nations that they would have received at home.

The rulings prompted a protracted exercise to develop a framework for patients' rights, which initially culminated in a 2008 proposal (www .aer.eu/fileadmin/user_upload/MainIssu es/Health/2008/crossborder_healthcare /EN-Com-crossborder-healthcare-direc tive.pdf) which was assailed as an initiative that would undermine a country's ability to control its health care system. Spain, Greece, Lithuania, Poland, Portugal and Romania lined up squarely against the proposal and it appeared dead in the water until the health ministers reached an agreement in Luxembourg on June 8.

Patient groups say "more needs to be done" for the directive to be effective.

'Patients' groups particularly call for mechanisms to be set in place for alternative means of payment that 
would not leave patients to bear the whole costs of cross-border healthcare up-front," Nicola Bedlington, director of the advocacy group European Patients' Forum, writes in an email.

"Without such mechanisms, the vast majority of the population would not be able to benefit in practice from the new rights granted to them under the Directive. On a positive note, we are pleased that the Council chose to retain Article 14 on eHealth, as effective patient information, shared electronically across borders, forms an essential support to patient safety in cross-border healthcare."

Others fear the directive will have a negative effect on postgraduate medical education, as well as on the medical job market.

"The impact of the directive on emedicine and telemedicine is particu- larly important, as there is great potential for the export of services to other jurisdictions resulting in diminished training and education opportunities in some areas. The directive should seek to protect the training opportunities in all jurisdictions or facilitate alternative training opportunities for the doctors deprived of training opportunities arising from the impact of the directive," stated the Permanent Working Group of European Junior Doctors in a position paper (www.juniordoctors.eu/pwg /files/PWG_09_52.pdf).

"Doctor migration will inevitably occur as the potential shift in workloads from one jurisdiction to another will require increased workforces in some areas and less in others. There is therefore a potential manpower shortage in some jurisdictions as a result of the directive while at the same time there will be increased competition for training opportunities in both jurisdictions," the paper added.

But the working group nevertheless appears on side with the directive. It "will now attempt to achieve a common position along with the other European medical organizations," says President Dr. Bernardo Bollen Pinto.

The compromise draft directive must still be approved by the European Commission, the Council of the European Union and the European Parliament. The European Commission estimates that roughly 800000 patients travel abroad to another European nation for treatment each year. — Tiago Villanueva MD, Lisbon, Portugal

DOI:10.1503/cmaj.109-3290 